\title{
The challenge of teaching astronomy in developing countries
}

\author{
By Lesley Onuora
}

The Astronomy Centre, University of Sussex, Brighton BN1 9QL

\section{Introduction}

Having recently returned to England (where I am an Open University tutor) after having spent about 18 years teaching Physics and Astronomy at the University of Nigeria at Nsukka in the Eastern part of Nigeria, I find myself in an unusual position to understand the difficulties of teaching such a rapidly changing subject as astronomy in an isolated place like Nsukka. For example I have seen a great contrast between the OU Astronomy and Planetary Science course material and the few available text books at Nsukka. Although not very mathematical, the OU material includes a lot of the latest research results and theories, whereas at Nsukka the books have hardly changed in the past 20 years.

I am aware that the Astronomy group at Nsukka is not unique. There are other small isolated groups of astronomers (or in some cases only a single astronomer) around the world who are trying to interest their students in astronomy against great odds. These astronomers appreciate the importance of astronomy in awakening interest in science and thus strengthening the basic sciences and developing technological progress. However Governments and even some international agencies often take the view that astronomy is a luxury that is not needed by such developing countries and therefore give little or no support to these efforts.

\section{Main Problems}

Apart from the lack of teaching materials, extremely limited access to computers and generally poor infrastructure, the one major problem is the extremely poor communications. Often phone, fax and mail do not work reliably, and needless to say there is no e-mail or internet. Access to the World Wide Web is almost taken for granted throughout the world and it is often not realised that the internet is not available universally. It is only since my return to England that $I$ have been able to fully appreciate what is being missed. At the recent United Nations/European Space Agency Workshop on Basic Space Science held in Sri Lanka, discussions were held about astronomical software packages available free of charge on the WWW. Also the availability of astronomical data archives was discussed. This would mean that astronomers in developing countries would be able to do research using the latest data and would not necessarily need their own telescopes. Advance information about scientific papers to be published, conferences planned etc. are all abailable. I am sure we will hear a lot in this colloquium about the plans of the Open University and others to use computers in future for distance teaching. In fact the time may soon come when a lot of information will not be available in hard copy. This is very worrying for astronomers in developmeing countries who do not have access to the internet and will therefore fall even further behind with respect to developed countries.

As I have already mentioned, books are out of date and in any case are not sufficient for the number of students. This places a great responsibility on the lecturer since the only real information that the students get comes from the lecturer. It is a form of distance learning, but in this case the students and lecturer are isolated together! 
It is therefore of great importance that the lecturers concerned attend international conferences, workshops, short courses etc. in order to keep up to date. Sponsorship for such activities is a major problem. The IAU has helped a great deal in this regard and have continued to show their concern about the plight of astronomers in some countries.

One might think that the obvious solution to the lack of teaching materials is for the lectureres in the country concerned to write text boks suitable for their students. However, the problem is an economic one of publishing books of suitable quality at prices affordable by the student. The number of students studying astronomy is too few to be able to convince a publisher to produce such a book.

\section{Present and future astronomy teaching}

The Department of Physics and Astronomy at the University of Nigeria teaches astronomy at both undergraduate and postgraduate levels. All physics undergraduates take an introductory course in astronomy with the option of doing more advanced courses and a project in their final year. It has been my experience that the students are very enthusiastic about their usually first exposure to astronomy, even when taught under such difficult conditions, especially if the lecturer is able to tell them about some of the latest observations and results. Astronomy programmes on the BBC World Service are a useful source of such information. Complimentary copies of some journals, including the Sky and Telescope, which arrive very erratically are immensly useful as are the reprints sent by some observatories.

Availablility of the internet would revolutionize both astronomy research and teaching in developing countries. This has been discussed repeatedly at United Naions/European Space Agency Workshops on Basic Space Science (e.g. Nigeria, 1993, Egypt, 1994).

Astronomy teaching is continuing and in fact gaining momentum in Nigeria. Three other universities are starting astronomy programmes, two of these initiated by doctoral graduates in astrophysics from the University of Nigeria. Recently a collaboration has been started between astronomers in South Africa and the Space Research Centre at the University of Nigeria. It is hoped that this will continue with future plans for some Nigerian postgraduate students to carry out observation projects in South Africa. It is also hoped to foster more interaction between astronomers throughout Africa. The UN/ESA Workshops held in Nigeria and Egypt as well as meetings held by the IAU Working Group on the World Wide Development of Astronomy have helped in this direction. 